\title{
Implantation of TUBOLUZ natural lighting system in a bottled gas cooking company in Amazonas
}

\author{
Izabel Pinheiro Andion ${ }^{1}$, Marcelo da Silva Andion ${ }^{1}$ \\ ${ }^{1}$ Universidade Paulista de Manaus. Avenida Mário Ypiranga, 4390, Parque 10 de novembro. Manaus-AM - Brasil.
}

Email: marceloandion1@gmail.com

Received: December $16^{\text {th }}, 2017$

Accepted: January $16^{\text {th }}, 2017$

Published: March 30th 2017

Copyright (C2016 by authors and Institute of Technology Galileo of Amazon (ITEGAM) This work is licensed under the Creative Commons Attribution International License (CC BY 4.0).

http://creativecommons.org/licenses/by/4.0/ (c) (1) (9) Opean Actes:

\begin{abstract}
We experience a time when the planet is experiencing a power crisis, the search for alternatives that reduce consumption is the obligation of all. Today more than ever, we need to offer conditions so that energy is used in the most rational and least costly possible way, taking advantage of natural resources in contrast to the use of conventional electricity in buildings, housing industries and companies, for they can remain competitive in the market, and mitigate environmental impacts from the use of conventional electricity. This work has the general objective to present the case and the solution for reducing power consumption in a gas filling plant in the city of Manaus. The specific objectives of the implementation of this new system will be presented throughout this work.
\end{abstract}

Keywords Natural lighting. Energy saving. Economic scenario. Environment.

\begin{abstract}
RESUMO
Vivenciamos uma época em que o planeta vive uma crise de energia, a busca por alternativas que diminuam o consumo é obrigação de todos. Hoje mais do que nunca, é preciso oferecer condições para que a energia seja utilizada da forma mais racional e menos dispendiosa possível, aproveitando os recursos naturais em contrapartida ao uso da energia elétrica convencional em edifícios que abrigam indústrias e empresas, para que com isso, as mesmas possam se manter competitivas no mercado e ainda mitigar impactos ambientais advindos do uso da energia elétrica convencional. Este trabalho, tem o objetivo geral de apresentar o estudo de caso e a solução apresentada para a redução do consumo de energia elétrica em uma planta de enchimento de gás na cidade de Manaus. Os objetivos específicos da implantação deste novo sistema serão apresentados ao longo deste trabalho.
\end{abstract}

Palavras Chaves: Iluminação Natural. Economia de energia elétrica. Cenário econômico. Meio ambiente.

\section{INTRODUÇÃO}

A incorporação da variável ambiental se apresenta como um fator importante a ser considerado no planejamento estratégico das organizações, podendo, em função das características do mercado, constituir-se em vantagem comercial.
O problema político econômico, no setor elétrico brasileiro, traz consigo um aumento no tarifário de energia elétrica, agravado com os condicionantes de aumento dos equipamentos e mão de obra, com isso, fazendo com que todo o processo de manutenção fique cada vez mais oneroso em todos os aspectos. $\mathrm{O}$ caso específico de área classificada com manuseio de gás inflamável faz com que todo esse processo de manutenção 
com luminárias com encapsulamento especial fique ainda mais delicado e demande uma mão de obra e tempo compatíveis à essa realidade.

Com a utilização dos recursos naturais, em particular a luz do sol, abundante em um pais tropical como o Brasil, podemos substituir parte do consumo voltado a iluminação, como forma de aumentar a sua competitividade, revertendo este ganho econômico na otimização de outros processos e mitigando impactos ambientais advindos da geração da energia fornecida pelas concessionárias.

A implantação do sistema de iluminação natural em ambiente empresarial pretende resolver todos os problemas mencionados acima. Segundo [1] "os edifícios não residenciais em geral são os que apresentam maior potencial de economia energética, nos usos finais de iluminação e ar condicionado". Elimina a periculosidade em áreas classificadas a zero por se tratar de uma luminária não elétrica, dispensa a utilização de energia elétrica para iluminação diurna, reduz significativamente a manutenção dos equipamentos, aumenta a vida útil dos equipamentos elétricos uma vez que serão utilizados somente nos turnos onde não há sol, tem um impacto térmico muito abaixo de qualquer luminária elétrica trazendo mais conforto térmico para o trabalhador, além de ter uma qualidade de iluminação insuperável para os funcionários.

\section{REVISÃO BIBLIOGRÁFICA}

Vivenciamos uma época em que, a busca por alternativas que diminuam o consumo é obrigação de todos. Hoje mais do que nunca, é preciso oferecer condições para que a energia seja utilizada da forma mais racional e menos dispendiosa possível, aproveitando os recursos naturais em contrapartida ao uso da energia elétrica convencional em edifícios que abrigam indústrias e empresas, para que com isso, as mesmas possam se manter competitivas no mercado e ainda mitigar impactos ambientais advindos do uso da energia elétrica convencional.

A iluminação natural ou zenital, tem a característica de gerar ambientes agradáveis e saudáveis, tendo em vista que a sua presença nos ambientes pode diminuir ou até mesmo eliminar germes, bactérias e fungos, fazendo com que a presença de mofo seja reduzida, evitando assim que aconteçam doenças geradas por estes tipos de agentes.

Os sistemas de iluminação zenitais que são formados por superfícies horizontais, requerem maior manutenção que os sistemas de superfícies verticais, tendo em vista que os níveis de transmissão da energia solar reduzem rapidamente, devido ao acúmulo de poeira, fator que reduz com a inclinação da superfície, de forma que a limpeza é realizada por meio das chuvas que escorrem por elas [2].

A localização dos sistemas de iluminação zenitais normalmente é nos planos horizontais de cobertura das edificações. De forma geral, são utilizados em casos onde se requer uma iluminação mais uniforme e onde não é possível utilizar iluminação através de aberturas laterais [3].

Uma razão importante para a utilização da iluminação zenital é a facilidade de colocar a iluminação natural na posição em que se deseja, facilitando o layout do local. Destaca-se também que o sistema é de fácil integração com a iluminação artificial, pois a iluminação pode ser instalado no espaço vindo do forro, em ambos os casos [3].
O custo inicial para a instalação da iluminação zenital é elevado, o que representa uma barreira para sua instalação. Igualmente, em alguns casos, apresenta maiores dificuldades para limpeza, além de possibilitar dificuldade para o controle de infiltrações das chuvas [4].

A utilização da iluminação natural como sistema de ventilação passiva também é possível, facilitando a renovação adequada do ar e evitando a presença de odores desagradáveis no ambiente [5].

Também pode ser considerada como uma das características deste tipo de iluminação, a distribuição de forma uniforme no espaço, que ocorre por meio da utilização da difusão da luz natural, evitando o contraste excessivo da iluminância no ambiente [6].

Já na perspectiva do desenvolvimento sustentável, devem ser contemplados dois aspectos importantes, que são: uso racional de combustíveis que se esgotam (não renováveis) e substituição evolutiva destes por energéticos do tipo renovável. A energia solar, neste ponto, pode contribuir de forma decisiva para o desenvolvimento sustentável [7].

A utilização de sistemas de iluminação natural zenital permite o ganho imediato de iluminâncias no ambiente. O ingresso e incidência da radiação solar direta pode alterar este padrão, dependendo da configuração do ambiente [8].

De acordo com a abertura da área, os sistemas de iluminação natural zenitais apresentam maior eficiência luminosa, sendo suficiente para a iluminação total do ambiente, tornando desnecessária as aberturas laterais [9].

Para [4] os ângulos externos de instalação da superfície captadora são fatores relevantes para o resultado da captação de e distribuição das iluminâncias no ambiente.

Segundo [10], um dos aspectos importantes sobre a iluminação natural, é o índice elevado de radiação solar, captado nas superfícies horizontais dos sistemas, que pode gerar um aquecimento excessivo do ambiente. Desta forma, um dos grandes desafios para a instalação da iluminação natural é encontrar a relação adequada entre os níveis de iluminação captados e os ganhos térmicos gerados, sendo necessário que cada projeto seja planejado de forma a utilizar as melhores características para aquele ambiente[11].

A figura do projetista, na elaboração de projetos com iluminação natural é fundamental para o desempenho do projeto. Um dos maiores desafios para este profissional, será a dificuldade de controlar o aspecto térmico. No verão, onde as temperaturas são mais altas, dependendo da instalação das aberturas, o ambiente pode ficar com temperaturas por demais elevadas, causando desconforto térmico. Já no inverno, esta característica seria inversa [4].

Para [8] enfatiza a necessidade de se levar em conta a enorme carga térmica que existe sobre as coberturas dos edifícios. Para [12] é necessário que seja projetado de forma correta o dimensionamento das aberturas, de forma a se obter somente a quantidade de luz necessária ao ambiente, sem ganho extra de calor, de forma a evitar que o ambiente fique desagradável.

Com o aprofundamento das pesquisas na área de iluminação, novos sistemas vêm sendo estudados. Os sistemas de iluminação precisam estar baseados em dois conceitos simples: aproveitar o potencial do brilho da luz do sol e possibilitar o redirecionamento do fluxo luminoso de acordo com a necessidade do local. 
Os sistemas de iluminação solar permitem a otimização e a distribuição da luz natural em um espaço, permitindo ainda o controle da iluminação direta da radiação solar e também o controle de problemas que possam ser gerados nos aspectos de conforto térmico-luminoso do usuário [1].

De acordo com [13] quanto maior for o ângulo da altura solar, maior será a incidência de radiação da luz natural disponível. Em condições de céu claro, o desempenho dos sistemas de iluminação natural zenital, irá depender da trajetória solar e dos ângulos de incidência direta da radiação sobre a superfície de captação. Nas regiões equatoriais, as aberturas horizontais mostram-se mais eficientes em relação à captação de radiação solar.

Existem vários tipos de iluminação natural, mas nenhum deles é universal e genérico às necessidades ambientais. Desta forma, não existe projeto de iluminação genérico, que possa ser utilizado para todo tipo de instalação. Cada um deve ser projetado, levando em conta as características do local e as necessidades específicas do projeto, sejam elas econômicas, físicas, funcionais ou climáticas. Para [13], a utilização de sistemas de iluminação natural podem ser apropriadas nos seguintes casos:

$\checkmark$ Quando a visão do céu é bloqueada pelo entorno da construção;

$\checkmark$ Para ambientes muito profundos, em que os sistemas de aberturas laterais, como janelas, não produzem a iluminação adequada;

$\checkmark$ Em climas ensolarados, para limitar a incidência direta da luz solar;

$\checkmark$ Em locais onde se faz necessário maior controle da iluminação como escritórios, bibliotecas, museus etc.

Para [6] a iluminação natural e suas aberturas zenitais são parte do projeto arquitetônico, enriquecendo o interior do espaço e sua percepção, por meio da luz captada e incorporada no ambiente.

Segundo [4] a iluminação natural é útil principalmente nos ambientes onde as paredes fazem parte da área de trabalho de construções amplas, ambientes onde a segurança é requerida através do fechamento das paredes laterais ou a visão do entorno direto é indesejada.

Historicamente são encontrados inúmeros exemplos de organizações que incorporam à sua estratégia a utilização de iluminação natural, como forma de aprimorar a iluminação interna de seus ambientes, de acordo com [14].

A iluminação com luz natural é fundamental para a definição do local de execução de tarefas, observando melhores condições de segurança e salubridade, podendo ser considerada fundamental na projeção de edificações, sendo o objeto de estudo de pesquisadores que buscam a solução de problemas ocasionados pelo ofuscamento, ou anda pelo contraste entre áreas iluminadas com este tipo de iluminação [15].

\section{MATERIAIS E MÉTODOS}

Com a implantação deste novo sistema de iluminação, os objetivos específicos foram:

$\checkmark$ Implantar o sistema de iluminação natural gradativamente na área de enchimento de botijões de gás, de forma a aproveitar a energia solar produzida; $\checkmark$ Reduzir os custos relacionados ao consumo de energia elétrica;

$\checkmark$ Minimizar os riscos em áreas classificadas.

Para implantação deste trabalho foi elaborado um plano de ação, com atividades que deveriam ser executadas de forma sequencial, até que a instalação total das novas luminárias fosse concluída.

Iniciou-se a instalação pelas áreas onde havia maior utilização de iluminação elétrica diurna. Esta fase deu-se em aproximadamente quatro dias de trabalho, já que a substituição pelas novas luminárias, só poderia ser realizada aos domingos, dia em que não havia atividade produzida na fábrica de enchimento.

Finalizado o processo de implantação inicial, passou-se a acompanhar diariamente o consumo de Energia Elétrica e avaliar a viabilidade ou não de continuar a implantação do novo modal. Depois de comprovada a viabilidade do novo modal, iniciou-se a substituição das demais luminárias da fábrica de enchimento. Esta segunda fase, deu-se em aproximadamente três meses de trabalho.

A estratégia de implantação do sistema em etapas, utilizando a fase de intervenção no telhado existente com máquinas de corte que gerem eventuais fagulhas nos momentos onde não há utilização da fábrica para o manuseio do gás de cozinha. Em seguida, a implantação dos sistemas no telhado já com intervenção, que não gera fagulhas em hipótese alguma, durante os dias da semana pela parte superior do telhado sem gerar interferências no processo fabril de enchimento das botijas.

Foi determinado os domingos como momentos em que não há utilização da fábrica para enchimento de botijões de gás como o momento oportuno para a cesura no telhado e implantação das chapas de suporte para as bases, e em seguida às quintas-feiras como momento para implantação dos sistemas nos locais onde houvera sido feita as implementações no telhado.

$\mathrm{O}$ retorno financeiro do investimento (ROI) realizado na implantação do novo sistema está estimado para um período entre 4 e 5 anos após a implantação do sistema.

Todos os colaboradores da empresa terceirizada que fez a implantação do novo sistema estão atualizados com os Cursos de segurança em altura, manuseio em eletricidade e outros cursos, necessários para a implantação do referido projeto. Igualmente, foi acompanhado a utilização de EPIs e equipamentos coletivos de segurança em todas as atividades.

Este trabalho, tem o objetivo geral de apresentar o estudo de caso e a solução apresentada para a redução do consumo de energia elétrica em um plana de enchimento de gás na cidade de Manaus, através da aplicação de tecnologias relacionadas à sustentabilidade e eficiência energética em iluminação buscando minimizar os impactos ambientais e emissão de gases nocivos ao meio ambiente.

\section{RESULTADOS E DISCUSSÕES}

O sistema de iluminação elétrico é utilizado atualmente na fábrica em dois turnos definidos para os dias de semana e dois turnos definidos para os sábados, conforme apresenta os dados da Tabela 1. 
Tabela 1: Horário de trabalho da Fábrica. USO DAFÁBRICA

\begin{tabular}{|l|c|c|c|}
\hline SEGUNDA ÅSEXTA & Início & Fim & Total \\
\hline Turno 1 & $07: 12$ & $17: 00$ & $09: 48$ \\
\hline Turno 2 & $17: 20$ & $01: 40$ & $08: 20$ \\
\hline TOTAL & & & $18: 08$ \\
\hline SÁBADOS & Início & Fim & Total \\
\hline Turno 1 & $7: 12$ & $11: 30$ & $4: 18$ \\
\hline Turno 2 & $14: 00$ & $22: 20$ & $8: 20$ \\
\hline TOTAL & & & $12: 38$ \\
\hline
\end{tabular}

Fonte: Os Autores, 2016.

Com isso, temos um total de uso semanal de 18:08h vezes os cinco dias da semana, totalizando 90:40h mais o sábado totalizando o uso da fábrica 103 horas e 18 minutos. Partindo disso, o uso da fábrica mensalmente é de 413 horas e 12 minutos e anualmente, utiliza-se a fábrica em média 4.958 horas e 24 minutos, conforme demonstrado na Tabela 2.

Tabela 2: Tempo total em horas utilizado na Fábrica.

\begin{tabular}{|c|c|c|c|c|}
\hline \multicolumn{5}{|c|}{ Uthlização do sistema elétrico de lluminação } \\
\hline Descriçäo & Semanal & Mensal & Mensal & Horas Ano \\
\hline Jso luminaçäo SEMTuboluz & $103 \mathrm{~h} 18 \mathrm{~m}$ & $413 h 12$ & 413,20 & 4.958 \\
\hline Iso luminatçäo COM Tuboluz & $46 h 40$ & $186 h 40$ & 186,67 & 2.240 \\
\hline
\end{tabular}

Fonte: Os Autores, 2016.

Na Tabela 2 pode-se perceber o efeito da redução na carga horária de uso na segunda linha, levando em conta o horário de autonomia do sistema de iluminação natural quando há sol, nesse caso, há uma redução de mais de 2.518 horas diante do uso convencional, com isso, uma redução de mais da metade do uso das luminárias elétricas.

A área fabril da empresa, antes da implantação do sistema de iluminação natural tem um consumo somente com as luminárias de aproximadamente $124 \mathrm{MW}$ no período de um ano. A equipe de manutenção apresentou um custo de manutenção com essas luminárias com encapsulamento blindado (obrigatórias para iluminação de áreas classificadas) de aproximadamente $\mathrm{R} \$ 5.000,00$ (cinco mil reais por mês) levando em conta a utilização do equipamento de iluminação convencional de 413 horas por Mês, tendo em vista que a vida útil das lâmpadas é medida em horas. A Tabela 3 apresenta a quantidade de lâmpadas utilizadas no local e o consumo das horas estimadas anteriormente.

Tabela 2: Utilização de luminária convencional.

\begin{tabular}{|l|c|c|c|}
\hline Sistema & Potência (W/h) & Quantidade & Pot. Total (Kw/h) \\
\hline Lamp. Eletr.250W* & 250 & 100 & 25 \\
\hline & \multicolumn{3}{|c|}{ Custos com o sistema de iluminação atual } \\
\hline Sistema & Cons. (Kw/h) / Ano & Manutenção /Ano & Custo Anual \\
\hline ED HIBAYY & 123.960 & R\$ 60.000,00 & R\$ 115.764,65 \\
\hline
\end{tabular}

Fonte: Os Autores, 2016.
Com a redução da utilização do sistema elétrico, a lâmpada vai ficar desligada por um período muito maior, mais da metade do período de utilização atual, com isso, pode-se considerar uma redução significativa na manutenção das lâmpadas uma vez que a vida útil tende a aumentar, refletindo diretamente nos custos com manutenção para o local.

Com as informações apresentadas até então, pode-se perceber as considerações específicas do uso da fábrica, custos com manutenção e consumo de energia elétrica. Para efeito de comparativo, foi utilizada a taxa atual de energia elétrica considerando o AME de 0,44986, conforme demonstrado na Tabela 4.

Tabela 3: Ensaio de consumo de Energia Elétrica em R \$ com a utilização de iluminação natural.

\begin{tabular}{|c|c|c|c|c|c|c|}
\hline \multicolumn{3}{|c|}{ Ensio como S Sistema Thouluz } & \multicolumn{2}{|c|}{ Redurionanial } & \multicolumn{2}{|c|}{ Retomo dolmestimento } \\
\hline Consumo |Kw//Ano & Manutencicio/Ano & Custohnal & Rouçäol (BST) & Red Perc. & Neses & Anos \\
\hline 56000 & RS36.000,00 & RS61.192,16 & R554,572,49 & 47,144 & 27 & Lanose3meses \\
\hline
\end{tabular}

Fonte: Os Autores, 2016.

Não estão sendo considerados para esse estudo os aumentos no tarifário de energia elétrica que certamente acontecerão no período, e certamente isso vai fazer com que o ROI aconteça antes do previsto, com a possibilidade de privatização da concessionária de energia elétrica, esse aumento pode chegar a mais que o dobro do valor hoje praticado, com isso, fazendo com que além do retorno do investimento, a empresa vai aumentar a lucratividade e competitividade no mercado por conta de não ter impactos tão elevados no tarifário de energia elétrica.

Na figura 1 observa-se a projeção de gastos utilizando o sistema convencional de energia elétrica para o período de dez anos. Após o período a empresa vai gastar R\$ 545.724,00 (quinhentos e quarenta e cinco mil, setecentos e vinte e quatro reais).

Figura 1: Projeção de gastos utilizando o sistema convencional de energia elétrica.

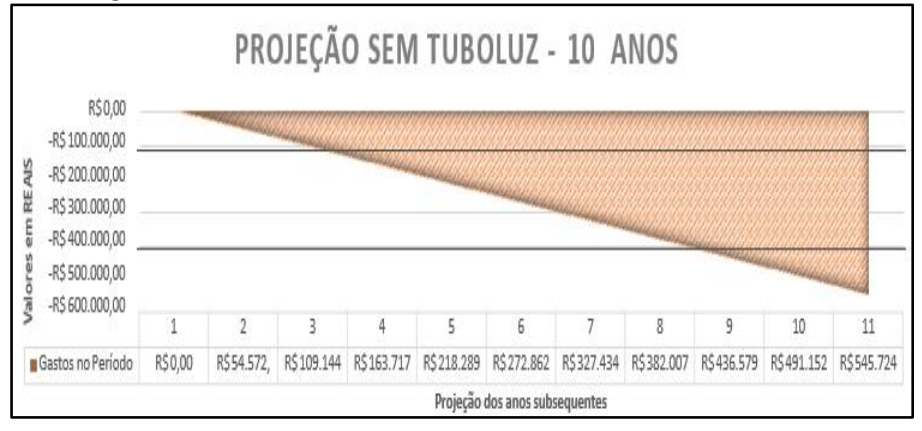

Fonte: Os Autores, 2016.

Na Figura 6 observa-se o investimento inicial de $\mathrm{R} \$$ $120.540,00$ (cento e vinte mil quinhentos e quarenta reais) e a recuperação do investimento em 2 anos e 3 meses. Após o período de dez anos, houve um ganho financeiro para a empresa 
de $\mathrm{R} \$ 425.184,00$. Este valor pode ser ultrapassado, se forem consideradas as reduções com a manutenção em lâmpadas do sistema convencional.

Figura 2: Recuperação do investimento com a implantação de iluminação natural.

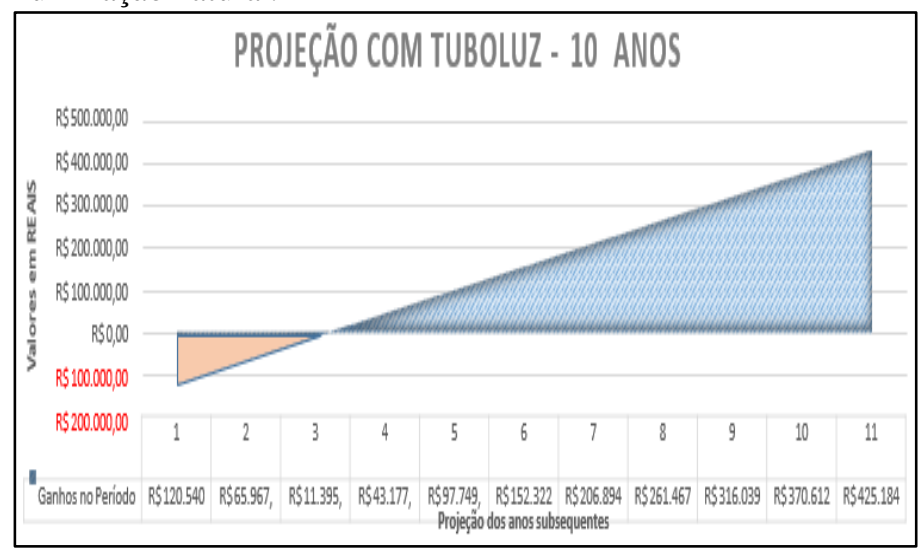

Fonte: Os Autores, 2016.

Nas Figuras de 3 a 5 observa-se o novo sistema de iluminação instalado na fábrica.

Figura 3: Sistema de Iluminação natural instalado.

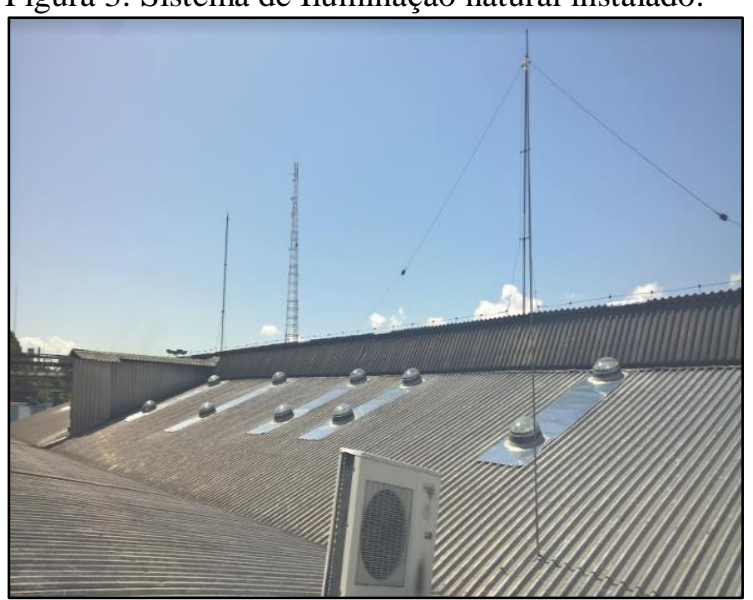

Fonte: Os Autores, 2016.

Figura 4: Sistema de Iluminação natural instalado.

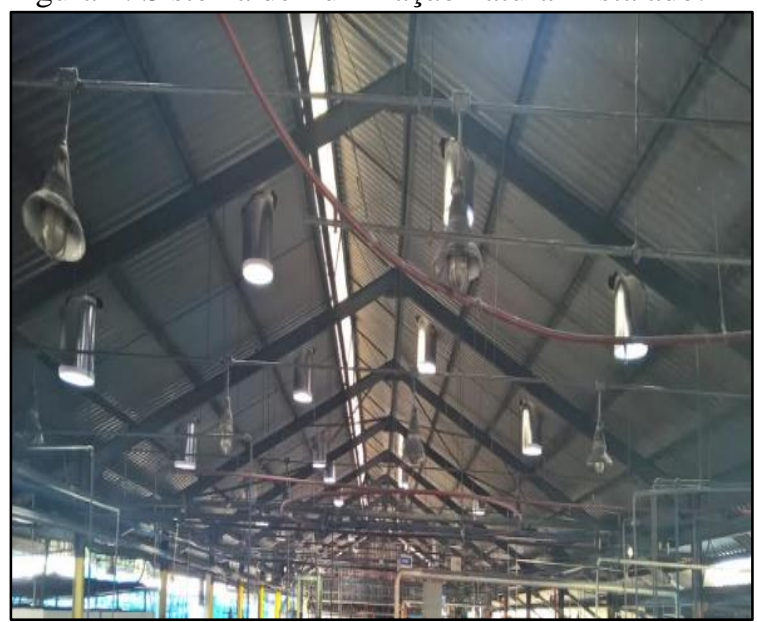

Fonte: Os Autores, 2016.
Figura 5: Sistema de Iluminação natural instalado.

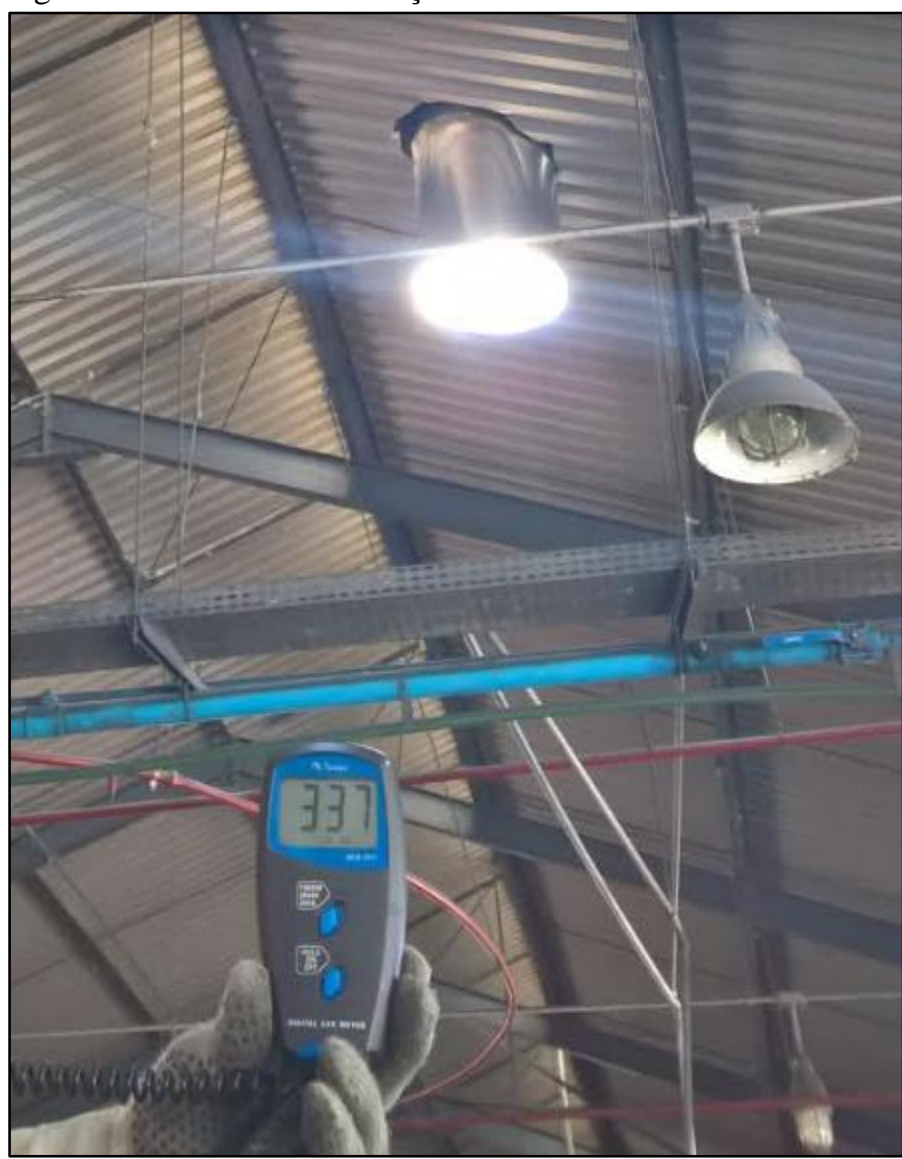

Fonte: Os Autores, 2016

As Figuras 6 e 7 apresentam a comprovação entre a luximetria e a temperatura, antes e depois de instalado o sistema de iluminação natural.

Figura 6: Luximetria e Temperatura do ambiente com o sistema convencional de iluminação.

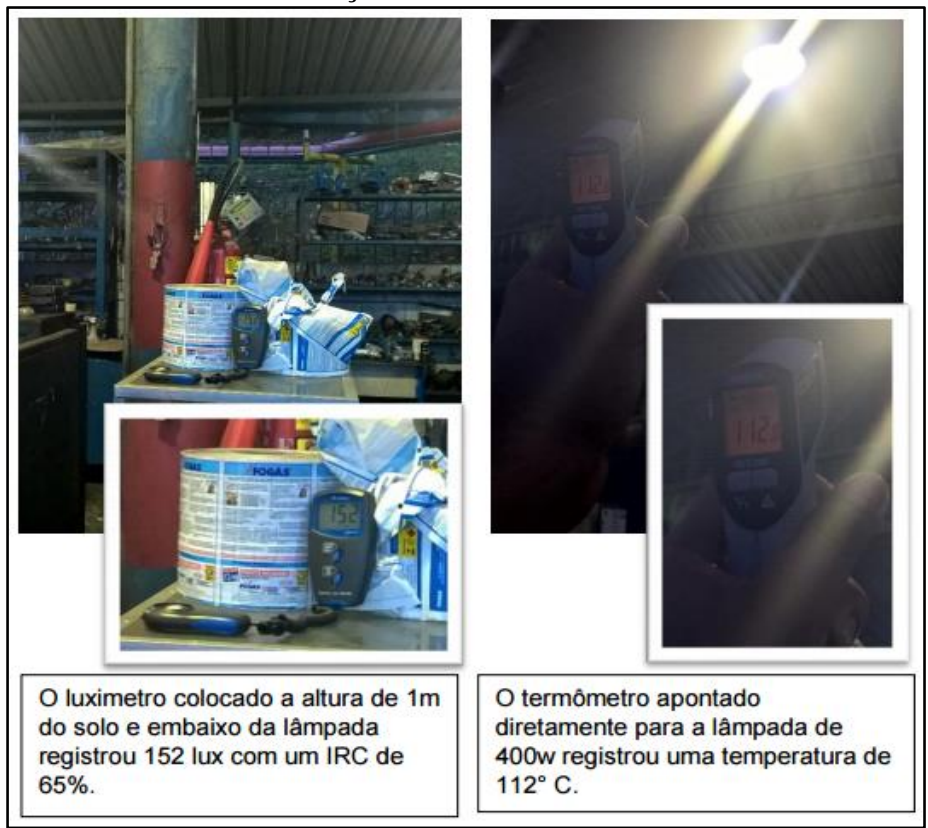

Fonte: Os Autores, 2016. 
Figura 4 - Luximetria e Temperatura do ambiente com o sistema de iluminação natural.

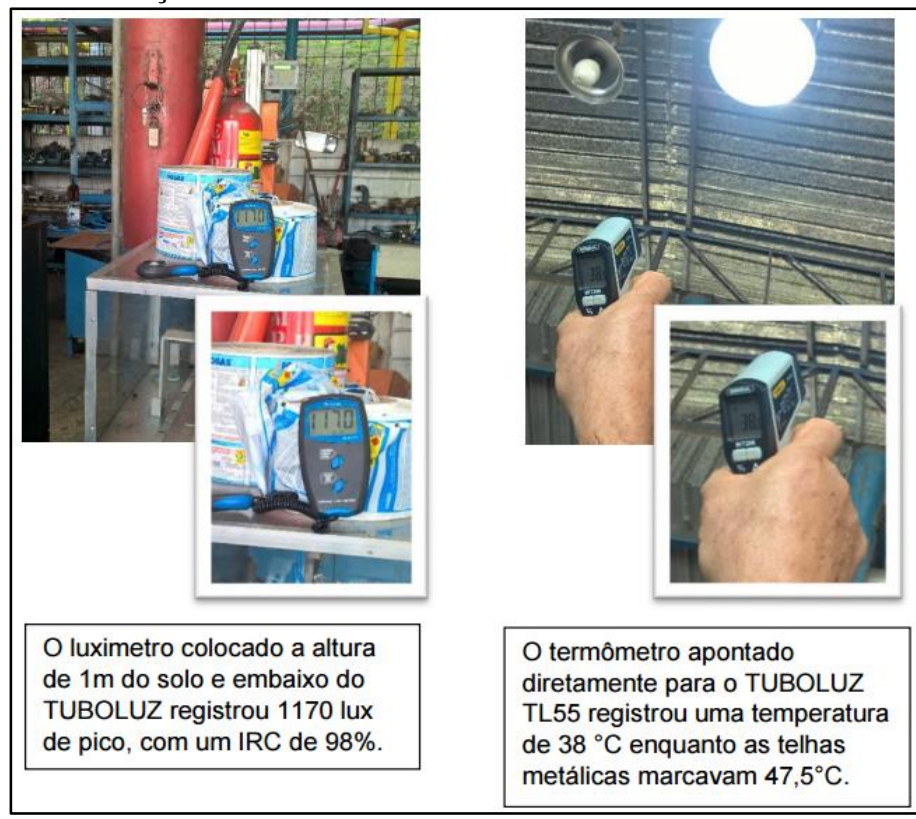

Fonte: Os Autores, 2016.

Na Figura 8 são mostrados os materiais utilizados para a implantação do sistema de iluminação natural na fábrica.

Figura 8: Material utilizado na instalação do sistema de iluminação natural.

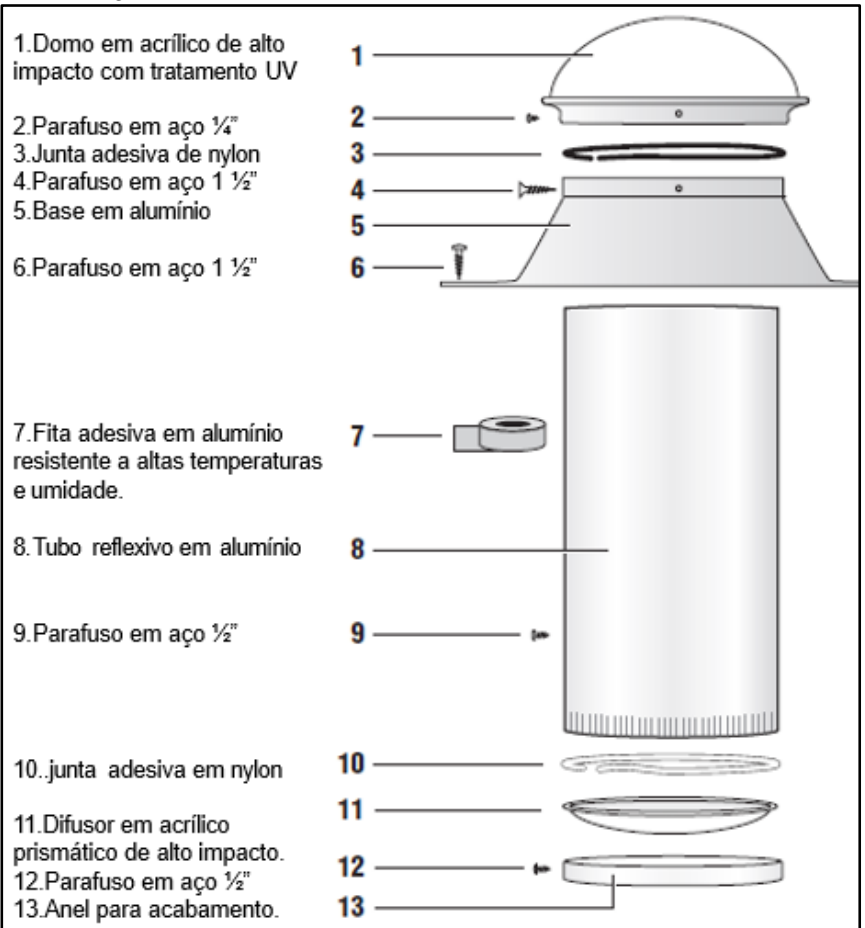

Fonte: Os Autores, 2016.

\section{CONCLUSÃO}

O uso de iluminação zenital ou luz do sol em ambientes fabril traz extrema vantagem competitiva e ganhos ambientais frente a iluminação artificial, visto que o sol está disponível na natureza em especial na região Amazônica, O estudo apresentado e implementado em galpão de enchimento de gás de cozinha demostra que houve aumento de lux e melhoria na temperatura do galpão.

Com o aumento dos custos nas tarifas de geração de energia elétrica o sistema de iluminação zenital ou iluminação natural com auxílio da luz do sol representa a médio e longo prazo um investimento extremamente rentável, pois a economia vai ser refletida na conta de energia da concessionária

Acompanhado a todas vantagens foi obtido ganhos relacionados a manutenção em área classificada, visto que toda $\mathrm{e}$ qualquer intervenção teria que ser com a planta totalmente parada e controlada através de medidores de gás para manter a segurança dos operadores envolvidos devido o risco de explosão, já com o novo modelo essa preocupação não se faz necessária pois não existe corrente elétrica o sistema funciona com os raios de luz que passam através de lentes e tubos com paredes especialmente polida que refletem e ampliam os raios do sol.

\section{AGRADECIMENTOS}

A Universidade Paulista pelo apoio à pesquisa.

\section{REFERÊNCIAS}

[1] GARROCHO, J. and C. AMORIM, Luz natural e projeto de arquitetura: estratégias para iluminação zenital em centros de compras. ENCONTRO NACIONAL DE TECNOLOGIA DO AMBIENTE CONSTRUÍDO, 2004. 10.

[2] Tregenza, P. and D. Loe, The design of lighting. 2013 Routledge.

[3] Okimoto, M.L.L.R., S.R. Marchi, and E.L. Krüger, Influência da Cor das Paredes e do Layout das Aberturas no Aproveitamento da Luz Natural do Ambiente. Estudos em Design, 2015. 16(1).

[4] Robbins, C.L., Daylighting. Design and analysis. 1985.

[5] Webb, A.R., Considerations for lighting in the built environment: Non-visual effects of light. Energy and Buildings, 2006. 38(7): p. 721-727.

[6] Sarmiento, P., Energía solar en arquitectura y construcción. 2007: RIL Editores.

[7] Rodríguez, P.S. and S.E. de la Costa Atlantica, Energía solar para todos. 1991: Centro El Canelo de Nos.

[8] Mascaró, L.A.R., Luz, clima e arquitetura. 1983: Livraria Nobel.

[9] Puppo, E., et al., Acondicionamiento natural y arquitectura: ecología en arquitectura. 1972: Marcombo.

[10]MOORE, F., Concepts and practice or architectural daylighting. New York: VNR Comp, 1985. 
[11] Lam, W.M., Sunlighting as formgiver for architecture. 1985.

[12] CABÚS, R.C. and F.O.R. PEREIRA, Avaliação através de método gráfico da distribuição de iluminâncias em ambientes. ENCONTRO NACIONAL DE CONFORTO NO AMBIENTE CONSTRUÍDO, 1997. 4: p. 328-332.

[13] Baker, N. and K. Steemers, Daylight Design of Buildings: a handbook for architects and engineers. 2014: Routledge.

[14] Chirarattananon, S., S. Chedsiri, and L. Renshen. Daylighting through light pipes in the tropics. Solar Energy, 2000. 69(4): p. 331-341.

[15]Junior, G. and S.F.C. Giardino. Estudo de redirecionamento da luz natural utilizando equipamento tipo "lightshelf", 2000. 